\title{
Mössbauer Characterization of Iron in Ancient Buried Trees Excavated from the Foothills of Mt. Chokai
}

\author{
Shigeru Yamauchi ${ }^{a, *}$, Yasuji Kurimoto $^{\mathrm{a}}$, and Yoichi Sakai ${ }^{\mathrm{b}}$ \\ anstitute of Wood Technology, Akita Prefectural University, Noshiro, Akita 016-0876, Japan \\ ${ }^{\mathrm{b}}$ Department of Chemistry, Daido University, Nagoya, Aichi 457-8530, Japan
}

Received August 18, 2017; Accepted December 26, 2017; Published online January 25, 2018

\begin{abstract}
The oxidation number and spin state of Fe in sample of ancient trees (umoregi trees) excavated from the foothills of Mt. Chokai in Japan were determined from the ${ }^{57} \mathrm{Fe}$ Mössbauer spectra. Moreover, basic structures of the Fe compounds were investigated using Mössbauer spectroscopy and complementary analytical techniques. The umoregi wood samples were prepared from the trunks of four tree species: Japanese cedar and Japanese zelkova which were brown and dark green, respectively; and Japanese oak and Japanese chestnut which were a pure black tone. Treatment with oxalic acid removed these characteristic colors from the samples. Mössbauer spectra were recorded at $293 \mathrm{~K}$ and $78 \mathrm{~K}$, and their absorption line-shapes were analyzed using a curve-fitting method. At 293 $\mathrm{K}$ and $78 \mathrm{~K}$, the respective isomer shifts of Fe were in the range of $0.21(3)-0.43(1) \mathrm{mm} / \mathrm{s}$ and $0.44(3)-0.53(1) \mathrm{mm} / \mathrm{s}$, and the respective quadrupole splitting values were in the range of $0.62(6)-1.06(2) \mathrm{mm} / \mathrm{s}$ and $0.84(5)-1.07(1) \mathrm{mm} / \mathrm{s}$. Although the resulting Mössbauer parameters confirmed that Fe in the umoregi wood was trivalent and its spin momentum number was $5 / 2$ (i.e. high-spin state), no changes in spectral shape due to paramagnetic relaxation were observed even at $78 \mathrm{~K}$. From this comprehensive investigation, it was determined that $\mathrm{Fe}^{3+}$ in Japanese oak and Japanese chestnut umoregi wood forms multinuclear complexes and has some differences in its first coordination sphere from $\mathrm{Fe}^{3+}$ in Japanese cedar and Japanese zelkova umoregi wood. Furthermore, it was suggested that the molecular structure of the $\mathrm{Fe}^{3+}$ complexes significantly affects the umoregi wood color tone.
\end{abstract}

\section{Introduction}

The Japanese term umoregi refers to ancient trees buried or submerged for a long period of time. In particular, this term implies that the trees, which have not been entirely denatured due to their isolation from sunlight and oxygen, were buried or submerged by natural phenomena (e.g., landslide, debris avalanche, ground subsidences) more than several hundred years ago. Umoregi generally refers to the trunk of the ancient trees. In English, bog wood, fossil wood (sub-fossil wood), and lignite have been used as translations for umoregi, however, they are not fully equivalent. This Japanese term does not belong to any scientific vocabulary and includes some ambiguity. In this study, we define umoregi wood as the trunk of an ancient buried tree that contains neither carbonized nor petrified components, although ancient trees are usually called umoregi even if they have undergone partial carbonization.

Most umoregi wood is brown or black in color, and sometimes deep green. Sufficiently sturdy umoregi wood can be used for construction and furniture, and they are traded as premium woody materials, because their characteristic colors or hues enhance their commercial value. The colors are due to chemical changes in the wood components that proceed slowly over a long period of time.

Umoregi trees have been found throughout Japan, and the degree of denaturation in them appears to be dependent on the tree species and the burial conditions, including the burial time and the soil type. In the last decade, Narita and co-workers have used chemical approaches to examine the essential oils contained in umoregi wood excavated in Japan..$^{1-5}$ However, these studies did not discuss the wood coloring

*Corresponding author. E-mail: sigeru@iwt.akita-pu.ac.jp, Fax: $+81-185-52-6924$ mechanisms.

From studies of iron-gall ink $\mathrm{k}^{6-10}$ and dark spots on timber due to Fe contamination, ${ }^{11-13}$ it has been recognized that the characteristic color of umoregi wood arises from reactions between Fe and polyphenols such as tannin. Only two studies ${ }^{14,15}$ on Fe in umoregi wood have been reported so far, and they made no mention of the coloring mechanism, although they investigated the chemical states of Fe in the wood using Mössbauer spectroscopy.

Our aim in this study is to determine the oxidation and spin state of $\mathrm{Fe}$ in umoregi wood and to obtain fundamental information about the molecular structure of Fe-containing chemical species. Here, we use ${ }^{57} \mathrm{Fe}$ Mössbauer spectroscopy and complementary analytical techniques to examine samples of umoregi wood obtained from trees excavated from the foothills of Mt. Chokai.

\section{Experimental}

2.1. Umoregi and raw wood samples. The umoregi trees used in this study were excavated in 2015 from Nikaho City in Akita Prefecture, Japan, located to the north-west of Mt. Chokai. The excavation site was within a construction area of the Nihonkai-Tohoku Expressway Nikaho interchange. It is conceivable that large-scale landslides occurred there and natural forests on the north-west side of Mt. Chokai to the present coast of Nikaho city were covered with soil and stone $c a .2500$ years ago. ${ }^{16,17}$

The umoregi trees were Japanese oak (OA; Quercus section Prinus, e.g. Quercus serrata or Quercus crispula), Japanese chestnut (CH; Castanea crenata), Japanese cedar (CE; Cryptomeria japonica), and Japanese zelkova (ZE; Zelkova serrata).

Hereafter, we refer to the tree trunks obtained by removing 
soil and bark from the excavated umoregi trees as "umoregi wood". After drying at ambient temperature for several months, umoregi wood was cut into ca. $9 \times 9 \times 1 \mathrm{~cm}^{3}$ blocks. The trunk samples of OA (Quercus serrata), $\mathrm{CH}, \mathrm{CE}$, and ZE, which are modern species, were prepared to compare with umoregi wood samples. We refer to the trunks of the modern trees as "raw wood".

2.2. Treatment with oxalic acid. Oxalic acid is widely used as a timber bleaching agent for Fe contamination. It is generally accepted that the bleaching is due to formation of Fe oxalates instead of $\mathrm{Fe}$ tannates, because $\mathrm{Fe}$ oxalates exhibit a yellow or pale-yellow hue, and hence we treated the umoregi wood with oxalic acid solution. The umoregi wood blocks were cut into smaller blocks and dried in air at $105{ }^{\circ} \mathrm{C}$ for 24 hours in an electric oven. The small blocks were immersed in aqueous oxalic acid solution ( $3 \mathrm{w} / \mathrm{w} \%$ ), and the glass beaker holding the solution and blocks was subsequently placed in a vacuum desiccator. The internal pressure was sufficiently reduced using a water-jet pump, and the desiccator was sealed for 3 hours. The blocks were taken out from the solution and dried in air for more than 3 days. Special-grade oxalic acid was obtained from Wako Pure Chemical Industries, Ltd.

\subsection{Preparation of sample powders for spectroscopic} analyses. The small blocks of umoregi wood and raw wood were crushed to powder using a ceramic ball mill. Wood powder that could be passed through an 18.5-mesh-sieve was used as a sample for the spectroscopic measurements. Soil was collected at the excavation site of a ZE umoregi tree. The soil was ground in a ceramic mortar after air-drying, and the soil powder was analyzed by X-ray fluorescence spectrometry.

2.4. X-ray fluorescence spectrometry. Elements with atomic numbers greater than 11 in umoregi wood and soil samples were determined by X-ray fluorescence spectrometry using a compact spectrometer (MESA-500, Horiba, Ltd.). Umoregi wood (0.36 - $0.79 \mathrm{~g})$ or soil (2.3 g) powder was placed in a cylindrical polytetrafluoroethylene cell with a diameter of $20 \mathrm{~mm}$. The sample chamber was evacuated using an oil- sealed rotary vacuum pump during measurements. X-ray irradiation was done at room temperature and the total measurement time was $2000 \mathrm{~s}$. The X-ray tube voltages were $15 \mathrm{kV}(1000 \mathrm{~s})$ and $50 \mathrm{kV}(1000 \mathrm{~s})$. Relative mass percentages of elements to total elements detected were estimated using a standardless fundamental parameter method ${ }^{18,19}$ from characteristic X-ray intensities.

2.5. Infrared photoacoustic (IR-PA) spectroscopy. The IR-PA spectra were obtained at $22 \pm 1{ }^{\circ} \mathrm{C}$ using a spectrometer (JIR7000W, JEOL, Ltd.) equipped with an IR-PA spectroscopy module (IR-PAS 1000, JEOL, Ltd.). The spectra were obtained from 300 accumulations with a spectral resolution of ca. $4 \mathrm{~cm}^{-1}$. A thin cell (diameter, $5 \mathrm{~mm}$ ) was filled with the wood powder, and photoacoustic signals were collected upon purging a cell bench with He gas. The moving-mirror velocity was fixed at $0.16 \mathrm{~cm} / \mathrm{s}$. Carbon black was used as a reference.

2.6. Mössbauer spectroscopy. ${ }^{57} \mathrm{Fe}$ Mössbauer measurements were carried out in a conventional transmission mode on a Mössbauer spectrometer (Model-222, Topologic System Co.) with a ${ }^{57} \mathrm{Co}(\mathrm{Rh})$ source $(925 \mathrm{MBq})$. Measurement temperatures were $293 \mathrm{~K}$ and $78 \mathrm{~K}$ and they were regulated using an Oxford cryostat DN-1726 with an ITC-601 temperature controller. Curve fitting of the Mössbauer spectra was performed by a nonlinear least-squares method using the MossWinn 4.0Pre. program, assuming that all spectra were composed of a doublet of Lorentzian-shaped peaks. The isomer shift (IS) and Doppler velocity scale were calibrated with respect to the sextet of $\alpha-\mathrm{Fe}$ at room temperature.

The umoregi wood sample thicknesses of CE and the other three were $c a .43 \mathrm{mg} / \mathrm{cm}^{2}$ and $c a .30 \mathrm{mg} / \mathrm{cm}^{2}$, respectively, and these allowed us to discuss Mössbauer absorption intensities semi-quantitatively.

\section{Results and Discussion}

3.1. Umoregi wood colors and bleaching with oxalic acid treatment. Figure 1 shows photos of the umoregi and raw wood samples, and the umoregi wood samples treated with
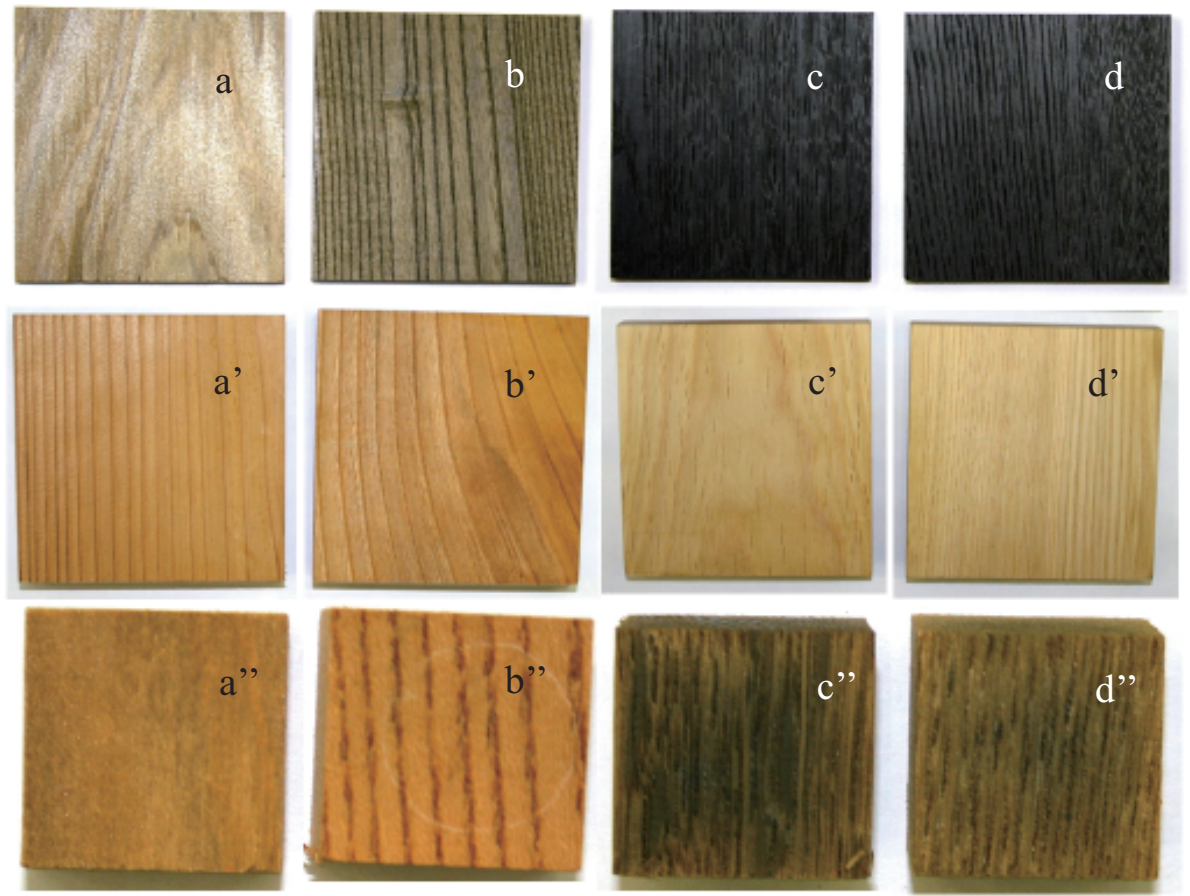

Figure 1. Umoregi and raw wood samples, and umoregi wood samples treated with oxalic acid. The top row is umoregi wood (a, CE; b, ZE; c, $\mathrm{OA} ; \mathrm{d}, \mathrm{CH}$ ), the middle row is raw wood (a', CE; b', ZE; c', OA; d', CH), and the bottom row is umoregi wood treated with oxalic acid (a', CE; b', ZE; c", OA; d", CH). 
TABLE 1: Relative mass percentage of elements in umoregi wood and soil samples

\begin{tabular}{|c|c|c|c|c|c|c|c|c|c|c|c|}
\hline \multirow{2}{*}{ Sample } & \multicolumn{10}{|c|}{ Element wt $\%$} & \multirow{2}{*}{$\begin{array}{c}\text { Ash } \\
\text { content } \%\end{array}$} \\
\hline & $\mathrm{Mg}$ & $\mathrm{Al}$ & $\mathrm{Si}$ & $\mathrm{P}$ & $\mathrm{S}$ & $\mathrm{Cl}$ & $\mathrm{K}$ & $\mathrm{Ca}$ & $\mathrm{Mn}$ & $\mathrm{Fe}$ & \\
\hline $\mathrm{CE}^{*}$ umoregi & - & $2.0(1)$ & $12.8(1)$ & $0.2(1)$ & - & $0.3(2)$ & $1.1(1)$ & $39.9(2)$ & $1.9(1)$ & $41.2(2)$ & 0.62 \\
\hline ZE* umoregi & - & $1.4(2)$ & $22.4(2)$ & $0.5(1)$ & - & $1.4(2)$ & $1.0(1)$ & $34.0(2)$ & $0.1 * *$ & $38.6(2)$ & 1.38 \\
\hline OA* $^{*}$ umoregi & - & $4.8(1)$ & $11.7(1)$ & - & $13.5(1)$ & - & $0.8^{* *}$ & $14.4(1)$ & $1.0^{* *}$ & $53.7(1)$ & 1.31 \\
\hline $\mathrm{CH}^{*}$ umoregi & - & $0.7 * *$ & $4.4^{* *}$ & - & - & - & $1.1^{* *}$ & $21.5(1)$ & $0.3^{* *}$ & $72.1(1)$ & 2.73 \\
\hline Soil ${ }^{* * *}$ & $2.2 * *$ & $11.6(1)$ & $61.5(1)$ & - & $1.2^{* *}$ & - & $4.5^{* *}$ & $4.2 * *$ & $0.2^{* *}$ & $13.3^{* *}$ & - \\
\hline
\end{tabular}

*CE, Japanese cedar; ZE, Japanese zelkova; OA, Japanese oak; CH, Japanese chestnut.

**Standard deviation is less than 0.1 .

$* * *$ Gray soil was present at the excavation site of the ZE umoregi tree.

oxalic acid. In the top row, CE and ZE umoregi wood appeared as brown (khaki) and dark green (olive green), respectively. Umoregi wood of $\mathrm{OA}$ and $\mathrm{CH}$, which belong to the family of Fagaceae, exhibited a pure black tone. Therefore, the colors of umoregi wood may vary with wood species. By comparing with the raw wood shown in the middle row, we saw that the wood color changed drastically with the burial time, and the color of umoregi wood was unrelated to that of the raw wood.

The umoregi wood samples shown in Figure 1 were prepared about 15 months after tree excavation, and their Mössbauer and IR-PA spectra were recorded at roughly the same time. The color tones of CE and ZE umoregi wood had changed to brown and dark green, respectively, immediately after the excavation. However, we judged that their color tones slightly and gradually became deeper with time. As for OA and $\mathrm{CH}$ umoregi wood, no color tone changes with time could be observed by the naked eye.

As mentioned above, although no studies are available on the coloring mechanism of umoregi wood based on immediate evidence, it is commonly recognized that the color features of umoregi wood are due mainly to Fe compounds interacting with polyphenols such as tannin. This has been deduced from studies of the historical ink (iron-gall ink) ${ }^{6-10}$ or stains on timber caused by Fe contamination. ${ }^{11-13}$ The stains showed dark colors similar to those of umoregi wood. Moreover, it has been reported that the dark stains occur on timber owing to $\mathrm{Cu}, \mathrm{Cr}$, and $\mathrm{Mn}$ as well as Fe. ${ }^{20-22}$

The bottom row shown in Figure 1 presents umoregi wood pieces treated with oxalic acid which were cut from the umoregi wood blocks shown in the top row. In all the umoregi wood pieces, their characteristic colors vanished dramatically through this treatment. The CE and ZE umoregi wood turned colors close to those of their raw wood, and the pure black tone faded away from the $\mathrm{OA}$ and $\mathrm{CH}$ umoregi wood. From the disappearance of dark color, we anticipated that the coloring mechanisms in umoregi wood were similar to those in timber caused by Fe contamination.

3.2. Elements analysis of umoregi wood and soil samples. Table 1 summarizes the relative mass percentage of elements from $\mathrm{Mg}$ to $\mathrm{Pb}$ in umoregi wood and soil samples collected from the excavation site.

Tsuchiya et al. ${ }^{23}$ reported the content of minor elements in the wood and bark of various raw tree species including $\mathrm{CE}$, $\mathrm{ZE}$, and OA using inductively coupled plasma emission spectrometry. Wood and bark are organic matter, and the major elements constituting them are $\mathrm{C}, \mathrm{O}$, and $\mathrm{H}$. According to their study, $\mathrm{K}$ and $\mathrm{Ca}$ were major elements among metals, exceeding $1000 \mathrm{mg} / \mathrm{kg}$ in more than half of the wood samples. $\mathrm{Mg}, \mathrm{Si}$, and $\mathrm{P}$ were classified into a secondary group among the minor elements and their contents ranged from dozens to several hundred $\mathrm{mg} / \mathrm{kg}$. The Fe content in the wood samples was under $10 \mathrm{mg} / \mathrm{kg}$ and less than $\mathrm{Al}$ and $\mathrm{Sr}$.

The umoregi wood had not been degraded markedly as mentioned later, and hence $\mathrm{C}, \mathrm{O}$, and $\mathrm{H}$ should also be major elements. In contrast, $\mathrm{Fe}$ was a major element in all the umoregi wood samples among the elements detected using X-ray fluorescence spectrometry, and, in particular, the relative mass percentage of Fe in $\mathrm{CH}$ umoregi wood was more than $70 \%$. The elemental analysis indicated that Fe content in the soil was much higher than that in the raw wood samples. Thus, it can be assumed that Fe was transferred from the soil to the umoregi wood during the long burial period. Other transition metals, which are capable of causing color changes in umoregi wood, were negligible except for $\mathrm{Mn}$. Although the contents of $\mathrm{Mn}$ were larger than those of $\mathrm{Cu}, \mathrm{Ni}$, or $\mathrm{Pb}$, particularly in $\mathrm{CE}$ and OA umoregi wood, the relative mass percentages of $\mathrm{Mn}$ were an order of magnitude lower than those of Fe. Most Ca contained in the umoregi wood was expected to have been already present in the trees when they were buried.

We noted that the relative mass percentages of $\mathrm{Al}$ in the umoregi wood were much less than those of Fe despite the value of $\mathrm{Al}$ being close to that of Fe in the soil sample. This might be explained as follows. In general, $\mathrm{Al}^{3+}$ shows many similarities in chemical behavior to $\mathrm{Fe}^{3+}$ and all of the $\mathrm{Al}$ contained in the soil must be trivalent $\left(\mathrm{Al}^{3+}\right)$. However, our previous Mössbauer measurement revealed that the $\mathrm{Fe}^{2+} / \mathrm{Fe}^{3+}$ ratio in the soil was $c a .3 / 7,{ }^{24}$ and therefore $\mathrm{Fe}^{2+}$ might transfer to umoregi wood more easily than $\mathrm{Fe}^{3+}$.

Major elements of raw wood are $\mathrm{C}, \mathrm{O}$, and $\mathrm{H}$, as mentioned above, and the sum of their contents is about $99 \%$. These elements cannot be detected by X-ray fluorescence spectrometry. Thus, the relative mass percentages shown in Table 1 should be much larger than the absolute mass percentages. We adopted a simple calculation method to estimate roughly the absolute mass percentage of $\mathrm{Fe}$ in the umoregi wood samples. In particular, assuming that only elements with atomic numbers smaller than 11 were completely removed from ash by burning, we calculated the tentative absolute mass percentages of Fe based on Eq. (1):

$$
T P_{\mathrm{Fe}}=R P_{\mathrm{Fe}} \times A \times 1 / 100
$$

where $T P_{\mathrm{Fe}}, R P_{\mathrm{Fe}}$, and $A$ are the tentative absolute mass percentage, relative mass percentage, and ash content in a percent unit, respectively. The ash contents of $\mathrm{CE}, \mathrm{ZE}, \mathrm{OA}$, and $\mathrm{CH}$ umoregi wood samples were $0.62,1.38,1.31$, and $2.73 \%$, respectively, as reported in our previous work. ${ }^{24}$ The $T P_{\mathrm{Fe}}$ values obtained from Eq. (1) of CE, ZE, OA, and $\mathrm{CH}$ umoregi wood samples were approximately $0.3,0.5,0.7$, and $2 \%$, respectively.

Eq. (1) is an approximate calculation because metal elements should be contained as oxides in ash. We expect, however, that $T P_{\mathrm{Fe}}$ obtained from Eq. (1) is a useful tool to estimate the chemical states of Fe in the umoregi wood. 
3.3. Infrared photoacoustic (IR-PA) spectroscopy. Figure 2 depicts the IR-PA spectra over the $2000-750 \mathrm{~cm}^{-1}$ range of the umoregi and raw wood samples. It is difficult to obtain a fine IR spectrum from black or dark-colored samples such as degraded wood and charcoal using ordinary techniques because of non-resonant absorption. Photoacoustic spectroscopy is a suitable technique to measure the IR spectra of such samples. For example, by means of the IR-PA spectroscopic technique, we have studied the weathering of tropical woods, revealing that this method is a useful tool to follow chemical changes in functional groups, especially carbonyl, carboxyl, and phenyl groups. ${ }^{25}$

As seen in Figure 2, the IR-PA spectrum of the umoregi wood samples was analogous to that of the same species of raw wood except for the regions of $1800-1620 \mathrm{~cm}^{-1}$ and $1300-$ $1200 \mathrm{~cm}^{-1}$. We noted that there were no significant spectral differences between raw and umoregi wood samples in the vibrational bands due to phenyl groups of lignin $\left(1592 \mathrm{~cm}^{-1}\right.$ and $\left.1503 \mathrm{~cm}^{-1}\right)^{26,27}$ and saturated cyclic groups of cellulose or hemicellulose $\left(1450-1320 \mathrm{~cm}^{-1}\right.$ and $1180-1000 \mathrm{~cm}^{-1}$, respectively). ${ }^{26}$ Therefore, we could assume that the degradation of umoregi wood had not proceeded drastically during the 2500 -year-burial of these trees.

Remarkable spectral differences, however, appeared in two regions. A broad band around $1740 \mathrm{~cm}^{-1}$ was assigned mainly to $\mathrm{C}=\mathrm{O}$ stretching vibrations in carboxy $\mathrm{l}^{26}$ and unconjugated carbonyl $^{28}$ groups, and the band intensity of umoregi wood was much less than that of raw wood. The band of stretching vibrations attributed to conjugated $\mathrm{C}=\mathrm{O}$ groups ${ }^{28}$ was detected at $c a .1650 \mathrm{~cm}^{-1}$, and its intensity in umoregi wood seemed to be slightly less than in raw wood. Furthermore, it seemed that the band intensities in the region of $1300-1200 \mathrm{~cm}^{-1}$ for the

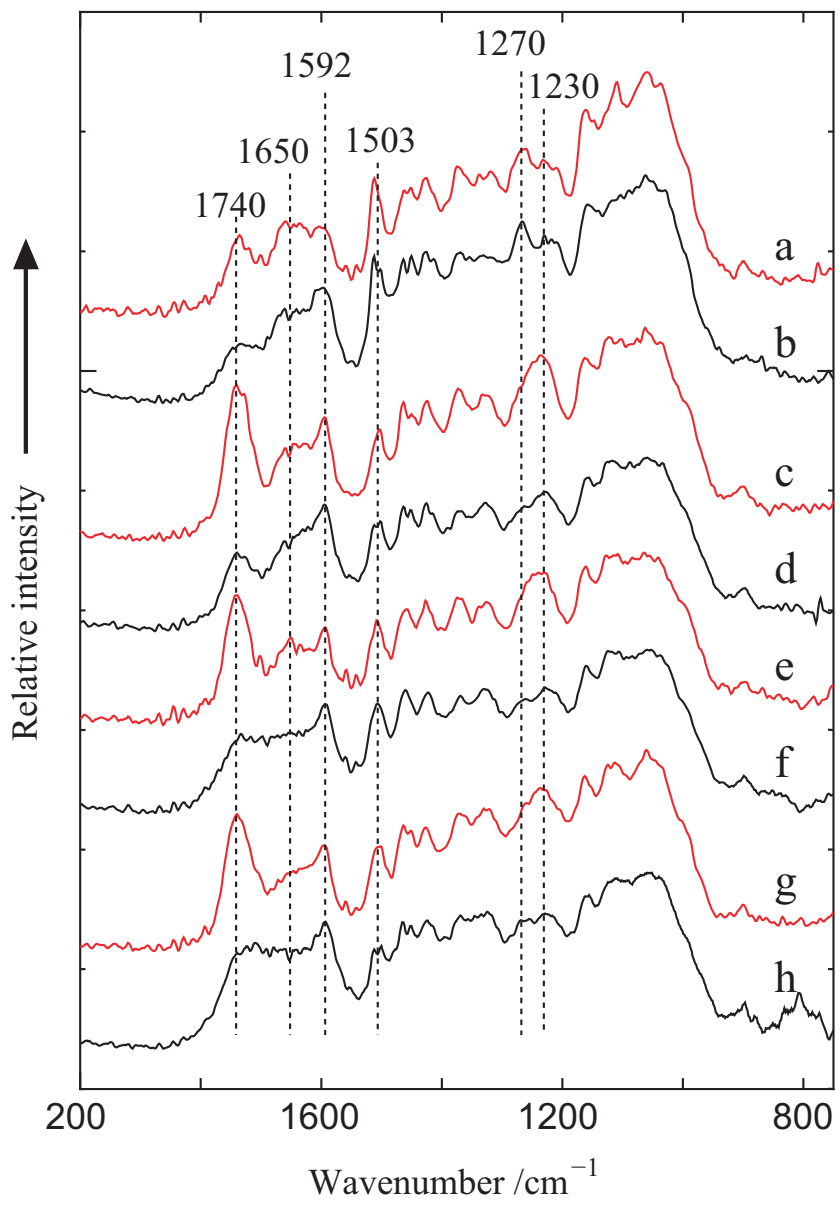

Figure 2. IR- PA spectra of raw and umoregi wood samples: a, CE (raw wood); b, CE (umoregi wood); c, ZE (raw wood); d, ZE (umoregi wood); e, OA (raw wood); f, OA (umoregi wood); g, CH (raw wood); h, CH (umoregi wood). umoregi wood samples except for CE were smaller than those of the raw wood samples. Several vibrational modes have bands in this region and one of them will be a stretching vibration of C-O in carboxyl groups. ${ }^{26}$ Thus, the IR-PA spectra of the umoregi wood samples reinforced the suggestion that some chemical changes occurred in carboxyl and/or carbonyl groups during the long burial period.

There are two possible chemical changes. One is decomposition of the functional groups, and the other is the occurrence of chemical interactions between the functional groups and their neighboring species. If $\mathrm{O}$ atoms included in the functional groups form hydrogen, ionic or coordinate bonds, the bands at 1740 and $1650 \mathrm{~cm}^{-1}$ would be shifted to considerably lower wavenumbers. ${ }^{29}$ It was, however, difficult to determine from the IR-PA spectra whether such shifts occurred.

3.4. Mössbauer spectroscopy. Figures 3 and 4 show the Mössbauer spectra of umoregi wood samples recorded at 293 $\mathrm{K}$ and $78 \mathrm{~K}$, respectively. The absorption intensities are substantially weak for almost all umoregi wood samples because of the low Fe contents $(0.3$ to $2 \%)$ as described in Section 3.2. Absorption lines in all the Mössbauer spectra consisted of a set of doublet lines, and no magnetic hyperfine splitting was observed even at $78 \mathrm{~K}$. Table 2 summarizes the Mössbauer parameters (IS; quadrupole splitting, QS; and line width, LW) calculated by curve fitting. The LW values were slightly but clearly larger ( $\sim 0.26 \mathrm{~mm} / \mathrm{s}$ in the present work) compared with ordinary $\mathrm{Fe}$ compounds. This enhancement of LW is explained later. In addition, from Figures 3 and 4, the Mössbauer absorption intensity was considered to be in the following order: $\mathrm{CE}<\mathrm{ZE}<\mathrm{OA}<\mathrm{CH}$, and this was in agreement with the order of $T P_{\mathrm{Fe}}$ (see Section 3.2).

The IS values of 0.21 to $0.43 \mathrm{~mm} / \mathrm{s}$ at $293 \mathrm{~K}$ indicated that Fe in all of the umoregi wood samples was high-spin $\mathrm{Fe}^{3+}$ or low-spin $\mathrm{Fe}^{2+} \cdot{ }^{30-32}$ The assignment to high-spin $\mathrm{Fe}^{2+}$ should be excluded, since the IS and QS values at $293 \mathrm{~K}$ (Table 2) ranged from $0.2 \mathrm{~mm} / \mathrm{s}$ to $0.5 \mathrm{~mm} / \mathrm{s}$ and from $0.6 \mathrm{~mm} / \mathrm{s}$ to $1.1 \mathrm{~mm} / \mathrm{s}$, respectively, and they were much smaller than those of most high-spin $\mathrm{Fe}^{2+}$ compounds. ${ }^{33,34}$ It seemed that all the IS and QS values at $293 \mathrm{~K}$ of $\mathrm{Fe}$ in the umoregi wood samples were within the shared ranges between high-spin $\mathrm{Fe}^{3+}$ and low-spin $\mathrm{Fe}^{2+} \cdot{ }^{33,34}$ However, the assignment to low-spin $\mathrm{Fe}^{2+}$ should also be excluded, because the umoregi wood and soil samples would contain little or no amounts of ligands inducing a large ligand field splitting such as $\mathrm{CN}^{-}, \mathrm{NO}_{2}^{-}$, or $\mathrm{NH}_{3}$. Therefore, the Fe in the umoregi wood samples was most likely to be highspin $\mathrm{Fe}^{3+}$. However, the QS values were somewhat larger than values typically seen for high-spin $\mathrm{Fe}^{3+}$ compounds.

The four types of umoregi wood were classified into two groups based on their IS and QS, as shown in Figure 5. Group 1 consisted of CE and ZE, and Group 2 consisted of OA and $\mathrm{CH}$. IS and QS of Group 1 were significantly smaller than those of Group 2. Moreover, the two groups differed from each other in color; Group 1 samples were brown or dark green, while Group 2 samples were pure black as seen in Figure 1. Hence, the first coordination sphere of Fe in Group 1 would be expected to be somewhat different from that in Group 2, even though $\mathrm{Fe}$ in both groups exists as high-spin $\mathrm{Fe}^{3+}$ species.

Group 1 showed a small but clear temperature-dependence for QS, although the QS values of Group 2 were independent of temperature. This suggested that $\mathrm{Fe}^{3+}$ species in Group 1 may undergo some structural change from $293 \mathrm{~K}$ to $78 \mathrm{~K}$, because QS of high-spin $\mathrm{Fe}^{3+}$ shows little or no temperaturedepndence. ${ }^{31}$ Moreover, the differences in IS of Group 2 between $293 \mathrm{~K}$ and $78 \mathrm{~K}$ were $c a .0 .1 \mathrm{~mm} / \mathrm{s}$ as shown in Table 2 , which was consistent with the second-order Doppler shift. ${ }^{30}$ However, the increases in IS of Group 1 at $78 \mathrm{~K}$ were too large to be accounted for as the second-order Doppler shift alone, 


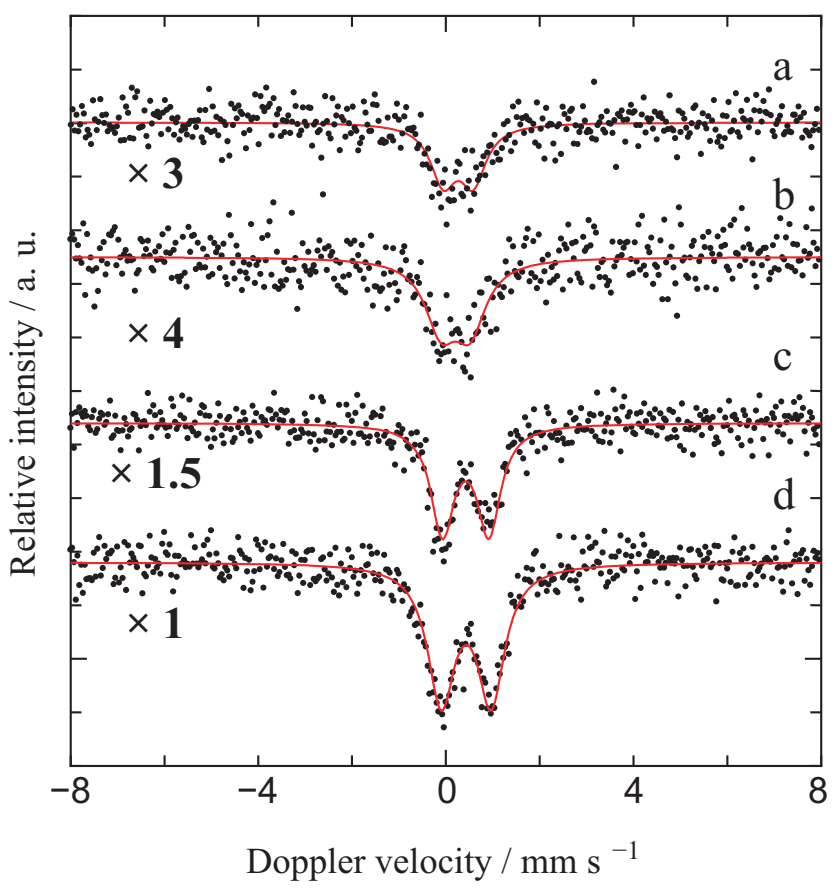

Figure 3. Mössbauer spectra at $293 \mathrm{~K}$ of umoregi wood samples: a, $\mathrm{CE}$; b, ZE; c, OA; and d, CH. Numerals in the spectra represent a relative magnification of intensity when the spectrum of $\mathrm{CH}$ is used as a reference. The percent absorption intensity is about $0.8 \%$ at the maximum for $\mathrm{CH}$.

TABLE 2: Mössbauer parameters of umoregi wood samples

\begin{tabular}{ccccc}
\hline $\begin{array}{c}\text { Umoregi wood } \\
\text { sample }\end{array}$ & $\begin{array}{c}\text { Temp. } \\
\mathrm{K}\end{array}$ & $\begin{array}{c}\mathrm{IS}^{* *} \\
\mathrm{~mm} \mathrm{~s}^{-1}\end{array}$ & $\begin{array}{c}\mathrm{QS}^{* * *} \\
\mathrm{~mm} \mathrm{~s}^{-1}\end{array}$ & $\begin{array}{c}\mathrm{LW}^{* * * *} \\
\mathrm{~mm} \mathrm{~s}^{-1}\end{array}$ \\
\hline \multirow{2}{*}{$\mathrm{CE}^{*}$} & 293 & $0.26(3)$ & $0.64(5)$ & $0.66(8)$ \\
& 78 & $0.44(3)$ & $0.84(5)$ & $0.68(7)$ \\
\hline & 293 & $0.21(3)$ & $0.62(6)$ & $0.82(15)$ \\
& 78 & $0.44(3)$ & $0.88(4)$ & $0.70(7)$ \\
$\mathrm{OA}^{*}$ & 293 & $0.42(1)$ & $0.99(2)$ & $0.60(3)$ \\
& 78 & $0.51(1)$ & $0.98(1)$ & $0.70(2)$ \\
\hline & 293 & $0.43(1)$ & $1.06(2)$ & $0.70(3)$ \\
$\mathrm{CH}^{*}$ & 78 & $0.53(1)$ & $1.07(1)$ & $0.67(1)$ \\
\hline
\end{tabular}

*CE, Japanese cedar; ZE, Japanese zelkova; OA, Japanese oak; $\mathrm{CH}$, Japanese Chestnut.

**Isomer shift, ***quadrupole splitting, ****line width.

and it appeared that there was some structural change taking place between $293 \mathrm{~K}$ and $78 \mathrm{~K}$.

It is well recognized, at room temperature, that IS is in the range of $0.3-0.6 \mathrm{~mm} / \mathrm{s}$ if coordinating atoms to $\mathrm{Fe}^{3+}$ form an octahedron (six-coordinated structure), and in the range of 0.2 $-0.4 \mathrm{~mm} / \mathrm{s}$ if a tetrahedron (four-coordinated structure) is formed. ${ }^{32}$ The IS of $\mathrm{Fe}^{3+}$ in Group 2 umoregi wood samples was in the former range, whereas the IS of $\mathrm{Fe}^{3+}$ in Group 1 umoregi wood samples was slightly less than $0.3 \mathrm{~mm} / \mathrm{s}$. It is, however, known that most Werner type $\mathrm{Fe}^{3+}$ complexes have an octahedral coordination geometry, except for halogenocomplexes.

On the other hand, for high-spin $\mathrm{Fe}^{3+}$ species, it has been reported that QS ranges at room temperature corresponding to the six-coordinated and four-coordinated structure ranges are approximately $0-1.1 \mathrm{~mm} / \mathrm{s}$ and $0-0.75 \mathrm{~mm} / \mathrm{s}$, respectively. ${ }^{34}$ As listed in Table 2, our QS values supported the finding that the coordination number of $\mathrm{Fe}^{3+}$ in Group 2 umoregi wood samples was six; however, they did not suggest a coordination

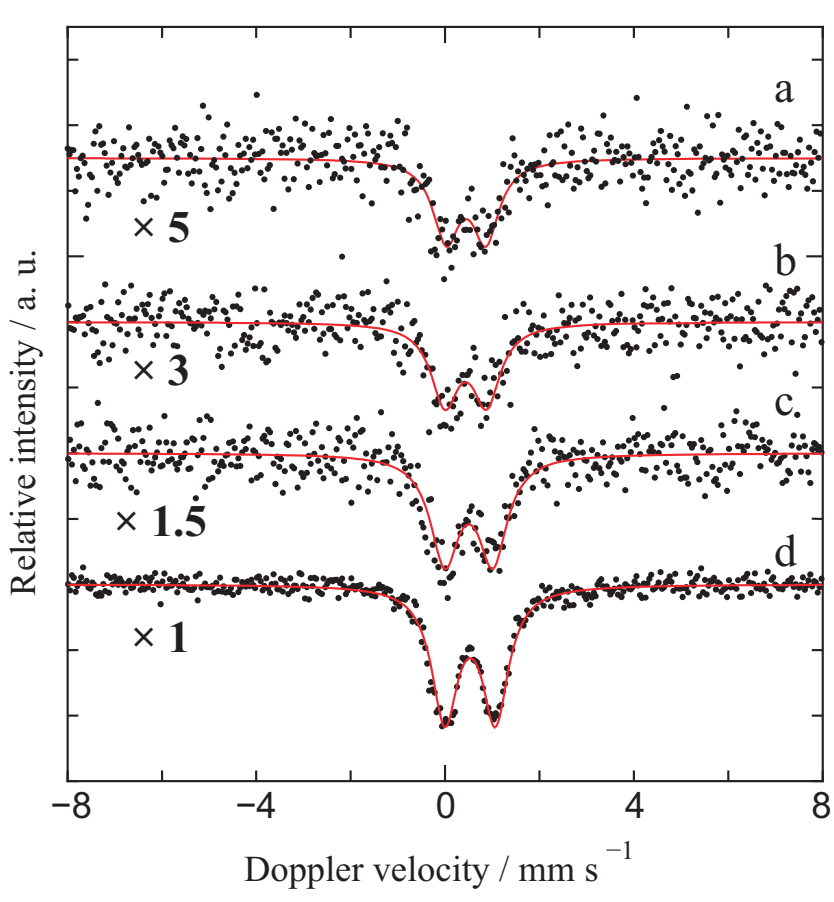

Figure 4. Mössbauer spectra at $78 \mathrm{~K}$ of umoregi wood samples: a, $\mathrm{CE}$; b, ZE; c, OA; and d, CH. Numerals in the spectra represent a relative magnification of intensity when the spectrum of $\mathrm{CH}$ is used as a reference. The percent absorption intensity is about $1.6 \%$ at the maximum for $\mathrm{CH}$.

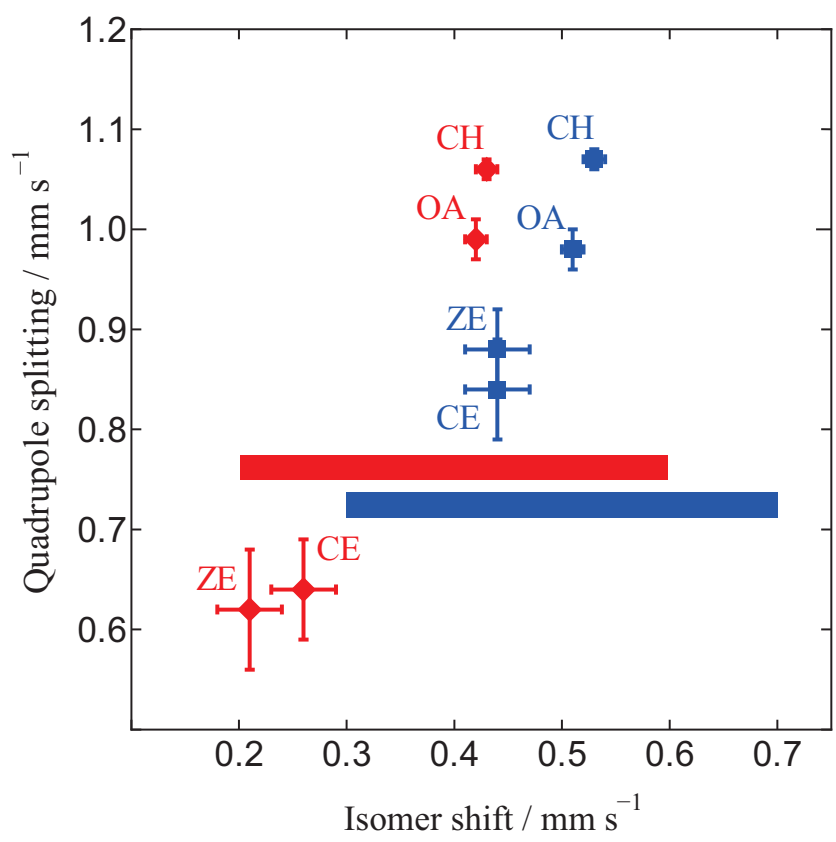

Figure 5. Isomer shift and quadrupole splitting at $293 \mathrm{~K}(\bullet)$ and 78 $\mathrm{K}(\mathbf{\square})$ of Fe in umoregi wood samples. The red band shows the IS range for high-spin $\mathrm{Fe}^{3+}$ at room temperature ${ }^{32,34}$, and the blue band shows that at liquid nitrogen temperature estimated from the secondorder Doppler shift ${ }^{30}$ on the basis of the former range.

number of $\mathrm{Fe}^{3+}$ in Group 1 umoregi wood samples.

Accordingly, the $\mathrm{Fe}^{3+}$ in Group 2 umoregi wood is certainly located at the center of an octahedron structure. In contrast, it is difficult to determine from Mössbauer parameters whether the first coordination sphere of $\mathrm{Fe}^{3+}$ in Group 1 umoregi wood is a tetrahedral or octahedral structure.

Several studies have addressed the reaction between $\mathrm{Fe}$ and polyphenols, and discussed the structure of polyphenol-Fe complexes. These studies are divided into two categories. The first is research into the effects of polyphenols in wood on 
Fe corrosion. ${ }^{6-10}$ Researchers have supposed that two kinds of mononuclear Fe(III) complexes bonded to tannins as a bidentate ligand are formed by the reaction with tannins extracted from wood, on the basis of Mössbauer spectroscopic analysis. The second category is a series of studies of historical ink (iron-gall ink). ${ }^{35-37}$ From both categories, it should be noted that a basic structure for a model compound for gallic acid$\mathrm{Fe}(\mathrm{III})$ complex was determined using an X-ray diffraction method. ${ }^{6,37}$ The gallic acid-Fe(III) complex has polynuclear structures, and a molecule of gallic acid forms three bonds between its three hydroxyl groups and two Fe atoms, and a chelate bond between its carboxyl group and another $\mathrm{Fe}$ atom. Fe atoms are located at the center of the octahedral structures. However, it will be very difficult to determine the structure of Fe compounds contained in the umoregi wood samples by $\mathrm{X}$-ray diffraction methods, because Fe concentrations are low and the crystals are microscopical if Fe compounds are crystallized.

Our Mössbauer data suggested that Fe species in Group 2 umoregi wood had multinuclear structures for which a unit contained two or more Fe atoms, because no changes in spectral shape due to paramagnetic relaxation were observed even at $78 \mathrm{~K}$ despite the presence of high-spin $\mathrm{Fe}^{3+}$. However, it was difficult from our Mössbauer spectral data to determine whether or not their molecular structures were analogous to that of the gallic acid-Fe(III) complex.

Paramagnetic relaxation phenomena in Mössbauer spectroscopy have been interpreted as the fluctuation of magnetic fields produced by electronic spins in paramagnetic compounds, and the fluctuation rate decreases as temperature decreases. This phenomenon is observable in high-spin $\mathrm{Fe}^{3+}$ and $\mathrm{Eu}^{2+}$ whose orbital momentum vanishes $(L \approx 0)$ as changes in Mössbauer spectra. Well-resolved magnetic hyperfine splitting clearly appears in Mössbauer spectra when a fully fixed magnetic field exists at a Mössbauer nuclide. Meanwhile, a magnetic field has no influence on Mössbauer absorption line-shape if its fluctuations are sufficiently fast. In both cases, Mössbauer spectra can be expressed as a combination of Lorentzian curves. However, at intermediate spin fluctuation rates comparable to the Larmor precession rate of the Mössbauer nucleus, it is known that the Mössbauer absorption line-shape becomes complicated through the relaxation effect and cannot be precisely approximated with Lorentzian or Gaussian curves. ${ }^{30}$

We previously reported the Mössbauer spectra of high-spin $\mathrm{Fe}^{3+38-43}$ and $\mathrm{Eu}^{2+44,45}$ compounds and their frozen solutions, and indicated that the electron-spin fluctuation rate decreases as the Fe-Fe or Eu-Eu distance increases due to less spin-spin dipole interaction. Specifically, we experimentally examined the Mössbauer line-shapes of tris( $\beta$-diketonato)Fe(III $)^{38,39}$ and hexakis(alkylurea)Fe(III) ${ }^{42}$ complexes, which have a six-coordinate octahedral structure in terms of the paramagnetic relaxation effect. The Mössbauer spectra of all these complexes showed an apparent single absorption line, but the line had wings on both sides and its line-shape was distinctly nonLorentzian. The bulkier the ligand of the Fe complex, the larger the wings were. In other words, the absorption lineshape broadened with increasing average $\mathrm{Fe}-\mathrm{Fe}$ distance in the complexes. The absorption line at liquid nitrogen temperature (78K) exhibited more obvious broadening compared with that at room temperature in each complex. Moreover, splittings due to magnetic hyperfine structures were observed in the Mössbauer spectra when $\mathrm{Fe}(\mathrm{III})(\mathrm{acac})_{3}\left(\mathrm{acac}, \mathrm{CH}_{3}\right.$ $\mathrm{COCHCOCH}_{3}{ }^{-}$) complexes were homogeneously dispersed in frozen solutions. ${ }^{38,40}$

In contrast, it was confirmed that the Mössbauer absorption line-shape of $\left[\left(\mu-\mathrm{CH}_{3} \mathrm{O}\right) \mathrm{Fe}(\mathrm{III})(\mathrm{dpm})_{2}\right]_{2}\left(\mathrm{dpm},\left(\mathrm{CH}_{3}\right)_{3}\right.$ $\left.\mathrm{COCHCOCH}\left(\mathrm{CH}_{3}\right)_{3}{ }^{-}\right)$, which is a dinuclear Fe complex, shows no significant changes when dispersed in a frozen solution despite the fact that the $\mathrm{Fe}^{3+}$ in the complex is in the high-spin state and located at the center of an octahedral structure. ${ }^{46}$ This was interpreted as an indication that the spin-spin dipole interaction was hardly weakened by dispersion in frozen solution, because the Fe-Fe distance in the dinuclear Fe complex unit was constant.

Accordingly, the Mössbauer absorption line of Fe in Group 2 umoregi wood samples should exhibit broad wings or some differences from Lorentzian curves if the $\mathrm{Fe}^{3+}$ species were mononuclear complexes. The reasons are as follows.

(1) $\mathrm{Fe}^{3+}$ species in Group 2 umoregi wood certainly have six-coordinate octahedral structures.

(2) Polyphenols, which will be bulkier than $\beta$-diketone and alkylurea molecules, likely form chemical bonds with $\mathrm{Fe}^{3+}$ as ligands.

In addition, the wings at $78 \mathrm{~K}$ should be broader and larger than those at $293 \mathrm{~K}$. Nevertheless, neither wings nor differences from Lorentzian curves were observed in the Mössbauer absorption of Fe in the umoregi wood samples and the absorption lines shown in Figures 3 and 4 were well explained by a superposition of two identical Lorentzian curves.

The wood components with pyrogallol groups that can form cross-linked structures by an O-Fe-O-Fe-O bond include several polyphenols containing tannins. As a result of the Mössbauer spectroscopic measurements, we concluded that $\mathrm{Fe}^{3+}$ formed multinuclear complexes with polyphenols in Group 2 umoregi wood. Furthermore, the large LW values allowed us to predict co-existence of two or more kinds of $\mathrm{Fe}$ complexes with similar structures, and this prediction was applicable to Group 1 umoregi wood.

On the other hand, the absence of a paramagnetic relaxation effect on the Mössbauer absorption line-shape could not be easily accepted as evidence that $\mathrm{Fe}^{3+}$ species in Group 1 umoregi wood were multinuclear complexes, because the coordination atoms to $\mathrm{Fe}^{3+}$ may form tetrahedral structures.

Our Mössbauer spectroscopic data indicated that $\mathrm{Fe}^{3+}$ species in Group 1 umoregi wood differ significantly from those in Group 2 umoregi wood in terms of their molecular structure, thereby reinforcing the suggestion that the molecular structure of $\mathrm{Fe}^{3+}$ species is an important factor determining the color tone of the umoregi wood. Further study is necessary to understand completely the molecular structures of $\mathrm{Fe}^{3+}$ species in different types of umoregi wood.

\section{Conclusion}

The results of the Mössbauer spectroscopic analysis described here confirmed that Fe in the umoregi wood samples had a $3 \mathrm{~d}^{5}$ electron configuration and its spin quantum number (S) was $5 / 2$ (high-spin state), and they indicated that the high-spin $\mathrm{Fe}^{3+}$ species in $\mathrm{OA}$ and $\mathrm{CH}$ umoregi wood samples exhibited octahedral symmetry and could be attributed to multinuclear compounds. Moreover, the temperature-dependence of IS and QS suggested that some structural changes might occur in $\mathrm{Fe}^{3+}$ species in $\mathrm{CE}$ and ZE umoregi wood samples between $293 \mathrm{~K}$ and $78 \mathrm{~K}$.

Comprehensive investigation of all the experimental results indicated that the $\mathrm{Fe}^{3+}$ complexes included polyphenols with pyrogallol groups as ligands, and suggested that their molecular structure was a governing factor for the umoregi wood color tone.

\section{Acknowledgement}

We are grateful to the Nikaho City Board of Education for the donation of the umoregi wood samples. 


\section{References}

(1) H. Narita, M. Yatagai, and T. Ohira, J. Essent. Oil Res. 18, 68(2006).

(2) H. Narita, and M. Yatagai, Org. Geochem. 37, 818 (2006).

(3) H. Narita, K. Huruhata, S. Kuga and M. Yatagai, Phytochem. 68, 587(2007).

(4) H. Narita, Mokuzai Kogyo 68, 330(2013).

(5) H. Narita, Wood Protection 42, 62(2016).

(6) C. H. Wunderlich, R. Weber, and G. Bergerhoff, Z. anorg. allg. Chem. 598/599, 371(1991).

(7) C. Krekel, Int. J. For. Doc. Exam. 5, 54(1999).

(8) B. Wagner, E. Bulska, B. Stahl, M. Heck, and H. M. Ortner, Anal. Chim. Acta 527, 195(2004).

(9) C. Burgaud, V. Rouchon, P. Refait, and A. Wattiaux, Appl. Phys. A92, 257(2008).

(10) C. Canevari, M. Delorenzi, C. Invernizzi, M. Licchelli, M. Malagodi, T. Rovetta, and M. Weththimuni, Wood Sci. Technol. 50, 1057(2016).

(11) W. Sandermann, and M. Lüthgens, Holz als Roh-u. Wérkst. 11, 435(1953).

(12) T. Kondo, H. Uto, and M. Suda, Mokuzai Gakkaishi 2, 221(1956).

(13) K. Takenami, Mokuzai Gakkaishi 10, 22(1964).

(14) S. Yamauchi, Y. Sakai, and H. Aimi, J. Wood Sci. 57, 549(2011).

(15) U. Bürck, F. E. Wagner, and A. Lerf, Hyperfine Interact. 208, 105(2012).

(16) H. Sakurai, W. Kato, Y. Takahashi, K. Suzuki, Y. Takahashi, S. Gunji, and F. Tokanai, Radiocarbon 48, 401(2006).

(17) S. Hayashi, Sabo \& Chisui 45, 80(2012).

(18) A. Kira, and N. Robson, Readout No. 22, 19(2001).

(19) W. T. Elam, R. B. Shen, B. Scruggs, and J. Nicolosi, Adv. X-ray Anal. 47, 104(2004).

(20) J. Wehrmann, Holz als Roh-u. Wérkst. 15, 325(1957).

(21) L. Plath, Holz als Roh-u. Wérkst. 16, 357(1958).

(22) K. Takenami, Mokuzai Gakkaishi, 10, 30(1964).

(23) Y. Tsuchiya, H. Shimogaki, H. Abe, and A. Kagawa, J. Wood Sci. 56, 53(2010).

(24) S. Yamauchi, Y. Kurimoto, and Y. Sakai, J. Nucl. Radiochem. Sci. 17, 1(2017).

(25) S. Yamauchi, Y. Sudiyani, Y. Imamura, and S. Doi, J. Wood Sci. 50, 433(2004).

(26) A. J. Michell, A. J. Watson, and H. G. Higgins, Tappi 48 ,
520(1965).

(27) U. M. Agarwal, J. D. McSweeny, and S. A. Ralph, J. Wood Chem. Tech. 31, 324(2011).

(28) I. R. Lewis, N. W. Daniel, N. C. Chaffin, Jr., and P. R. Griffiths, Spectrochim. Acta 50A, 1943(1994).

(29) K. Nakamoto, Infrared and Raman spectra of inorganic and coordination compounds Part B: Applications in coordination, organometallic, and bioinorganic chemistry, A John Wiley \& Sons, Inc., New Jersey, (2009).

(30) P. Gütlich, E. Bill, and A. X. Trautwein, Mössbauer spectroscopy and transition metal chemistry -Fundamentals and applications-, Springer-Verlag, Berlin, (2011).

(31) J. C. Travis, The electric field gradient tensor, in: An introduction to Mössbauer spectroscopy Ed. L. May, Plenum Press, New York, (1971).

(32)F. Menil, J. Phys. Chem. Solids, 46, 763(1985).

(33) N. N. Greenwood, and T. C. Gibb, Mössbauer spectroscopy, Chapman and Hall Ltd., London, (1971).

(34) R. E. Vandenberghe, and E. De Grave, Mössbauer spectroscopy, Eds. Y. Yoshida, and G. Langouche, SpringerVerlag, Berlin, (2013).

(35) J. Gust, and J. Suwalski, Corrosion 50, 355(1994).

(36) J. A. Jaén, J. De Obaldía, and M. V. Rodríguez, Hyperfine Interact. 202, 25(2011).

(37) R. K. Feller, and A. K. Cheetham, Solid State Sci. 8, 1121(2006).

(38) Y. Sakai, H. Nishioji, S. Yamauchi, and T. Tominaga, Radiochem. Radioanal. Lett. 53, 215(1982).

(39) S. Yamauchi, Y. Sakai, and T. Tominaga, Int. J. Appl. Radiat. Isot. 34, 977(1983).

(40) Y. Sakai, H. Nishioji, and T. Tominaga, Radiochim. Acta 36, 181(1984).

(41) S. Yamauchi, Y. Sakai, and T. Tominaga, Bull. Chem. Soc. Jpn. 58, 442(1985).

(42) S. Yamauchi, Y. Sakai, and T. Tominaga, J. Radioanal. Nucl. Chem. Lett. 119, 283(1987).

(43) S. Yamauchi, Y. Sakai, and T. Tominaga, J. Radioanal. Nucl. Chem. Lett. 146, 185(1990).

(44) S. Yamauchi, Y. Minai, and T. Tominaga, J. Radioanal. Nucl. Chem. Lett. 93, 238(1985).

(45) S. Yamauchi, T. Watanabe, and T. Tominaga, Radiochim. Acta 43, 51(1988).

(46) S. Yamauchi, Mössbauer spectroscopic study of magnetic relaxation in iron compounds, The University of Tokyo, 1983, Master's thesis. 